Res., Soc. Dev. 2019; 8(4):e1784961

ISSN 2525-3409 | DOI: http://dx.doi.org/10.33448/rsd-v8i4.961

\title{
A Orientação Educacional no Brasil e o contexto da rede municipal de ensino de
} Santa Maria, RS

The Educational Advising in Brazil and the municipal education network context of Santa Maria, RS

La Orientación Educativa en Brasil y el contexto de la red municipal de enseñanza de Santa Maria, RS

Janete Allassia Drebes Wouters

ORCID: https://orcid.org/0000-0001-5612-369X

Universidade Franciscana, Brasil

E-mail: janeteadw@gmail.com

Eliane Aparecida Galvão dos Santos

ORCID: https://orcid.org/0000-0002-3982-7297

Universidade Franciscana, Brasil

E-mail: elianeagalvao1@gmail.com

Recebido: 30/01/2019 | Revisado: 30/01/2019 | Aceito: 03/02/2019 | Publicado: 13/02/2019

\section{Resumo}

Esse artigo é um recorte da dissertação de Mestrado em Ensino de Humanidades e Linguagens da Universidade Franciscana/RS, da primeira autora. O texto tem como objetivo apresentar o contexto histórico da Orientação Educacional no Brasil, evidenciando a realidade do município de Santa Maria, RS, ao longo desse processo. A metodologia adotada consiste em uma pesquisa de abordagem qualitativa do tipo bibliográfica e documental. Deste modo, a partir dos momentos históricos tanto nacional como local, pode-se observar que a Orientação Educacional teve uma diversidade de funções que acarretou ao longo da história em desprestígio e discordâncias sobre o papel desse profissional na equipe gestora das escolas. Conclui-se que colocar em evidência o contexto histórico da Orientação Educacional é de fundamental importância para que o papel desse profissional seja valorizado, de modo que ele possa vir a contribuir com os desafios da gestão escolar, atuando como parte de uma equipe gestora.

Palavras-chave: Orientador Educacional; Ensino; Percurso Histórico; Legislação. 


\section{Abstract}

This article is a cross-section of the first author's Master's Thesis in Humanities and Languages Teaching at Franciscana University/RS. The goal is to present the historical context of the Educational Advising in Brazil evidencing the reality of the municipal of Santa Maria, RS, throughout this process. The methodology adopted consists of a qualitative research of the bibliographical and documentary type. Thus, from the historical moments both national and local, it can be observed that the Educational Advising had a diversity of functions that throughout the history has led in disrepute and disagreements about the role of this professional in the management team of schools. It is concluded that highlighting the historical context of Educational Guidance is of fundamental importance so that the role of this professional is valued, enabling the contribution to the challenges of school management, acting as part of a management team

Keywords: Educational advisor; Teaching; Historic Route; Legislation.

\section{Resumen}

Incluir o resu Este artículo es un recorte de la disertación de Maestría en Enseñanza de Humanidades y Lenguajes de la Universidad Franciscana / RS, de la primera autora. El texto tiene como objetivo presentar el contexto histórico de la Orientación Educativa en Brasil evidenciando la realidad del municipio de Santa María, RS, a lo largo de ese proceso. La metodología adoptada consiste en una investigación de abordaje cualitativo del tipo bibliográfica y documental. De este modo, a partir de los momentos históricos tanto nacionales como locales, se puede observar que la Orientación Educacional tuvo una diversidad de funciones que acarreó a lo largo de la historia en desprestigio y discordancias sobre el papel de ese profesional en el equipo gestor de las escuelas. Se concluye que poner en evidencia el contexto histórico de la Orientación Educativa es de fundamental importancia para que el papel de ese profesional sea valorado, de modo que él pueda venir a contribuir con los desafíos de la gestión escolar, actuando como parte de un equipo gestor.

Palabras clave: Orientador Educativo; la educación; Recorrido Histórico; Legislación.

\section{Introdução}

No Brasil, a Orientação Educacional teve um período de sucesso em que sua presença era obrigatória em todas as escolas do país de acordo com a Lei de Diretrizes e Bases (LDB) 5692/71. Entretanto, na década de 1980, este profissional acabou tendo demérito em seu trabalho, visto que o contexto obteve um cunho mais tecnicista e, posteriormente, a LDB 
9394/96 não trouxe mais essa obrigatoriedade. A partir disso, as escolas da rede municipal de Santa Maria também deixaram de ter um orientador educacional em seu quadro funcional, pois a Lei Municipal 4696/2003 passou a extinguir este cargo do plano de carreira do magistério.

Desta forma, este trabalho tem por objetivo apresentar o contexto histórico da Orientação Educacional no Brasil, evidenciando a realidade do município de Santa Maria, RS, ao longo desse processo.

Nesse sentido, a reflexão sobre o percurso transcorrido pela Orientação Educacional no Brasil e a legislação pertinente a ela, tornou possível perceber que as mudanças ocorridas também estão ligadas ao ensino e a gestão das escolas. Logo, influenciam na formação do aluno, pois a educação não se limita apenas ao ensino e a aprendizagem, mas também compreende a vida em sociedade.

Desse modo, pretende-se apresentar como a profissão de orientador educacional foi implementada no Brasil até a atualidade. Essa reflexão torna-se imprescindível uma vez que se entende como a Orientação Educacional no Brasil precisa ser valorizada, pois essa "[...]está cada vez mais comprometida com a educação no sentido de favorecer, promover os meios necessários para que se efetive uma educação de qualidade em todas as modalidades de ensino" (Grinspun, 2012, p. 7). A partir da reconstrução histórica é possível pensar em políticas públicas que venham a contribuir para qualificação dos processos formativos dos educandos.

O artigo encontra-se dividido em duas seções: primeiramente buscou-se contextualizar a origem da Orientação Educacional no Brasil, a partir de 1924, com sua instauração na cidade de São Paulo e, a partir desse ponto, as diretrizes que seguem. A segunda seção tem como objetivo discutir sobre o papel do orientador educacional no contexto municipal de Santa Maria, RS.

Mediante a isso, são apresentados elementos que discutem e destacam os aspectos legais da Orientação Educacional. Posteriormente, a trajetória percorrida pelos orientadores educacionais, o que abrange não só a perspectiva histórica, mas também o apontamento de caminhos para que se reestabeleça a importância da presença desse profissional no corpo docente das escolas municipais da cidade. 


\section{Contextualização histórica sobre a Orientação Educacional no Brasil}

No que se refere ao papel do orientador educacional é preciso ter o entendimento de que a função está atrelada ao grupo de gestão educacional da escola, de tal maneira que deve ser compreendida como a engrenagem do espaço escolar. Isto porque além de integrante da equipe gestora de uma escola, esse profissional pode ser o elo entre os setores da escola e da comunidade como um todo, uma vez que se prima pelo desenvolvimento integral do educando. Sendo assim, a Orientação Educacional atua de forma interdisciplinar visando o bem-estar da comunidade escolar.

Entretanto, este não foi seu primeiro objetivo, visto que possuiu um caráter inicial focado no processo vocacional do aluno e sofreu diversas modificações com o passar dos anos. Grinspun (2012) nomina os períodos cronológicos da Orientação Educacional de acordo com a Figura 1.

Figura 1 -Período Cronológico da Orientação Educacional

\begin{tabular}{|l|l|}
\hline $1920-1941$ & Período Implementar \\
\hline $1942-1960$ & Período Institucional \\
\hline $1961-1970$ & Período Transformador \\
\hline $1971-1980$ & Período Disciplinador \\
\hline Década de 1980 & Período Questionador \\
\hline A partir de 1990 & Período Orientador \\
\hline
\end{tabular}

Fonte: adaptado de Grinspun (2012)

Diante disso, os primeiros relatos sobre a Orientação Educacional no Brasil surgiram no ano de 1924, na qual sua função era exclusivamente voltada para a escolha profissionalizante. Nesse viés, com o professor Roberto Mange (1885 - 1955), iniciou o exercício da profissão em São Paulo, no Liceu de Artes e Ofícios em que tinha como objetivo selecionar e orientar os alunos matriculados no curso de Mecânica. Em 1931, ainda em São Paulo, foi criado oficialmente o primeiro Serviço Público de Orientação Profissional postulando o mesmo objetivo: que os alunos tivessem orientação na escolha do curso profissionalizante que iriam cursar em seu ensino secundário, sendo criado, nesse período, um Gabinete de Psicotécnica (Garcia, 1990).

Em 1938 o Instituto Nacional de Estudo e Pesquisa Educacionais (INEP) implantou a Orientação Educacional, que além do foco na orientação da escolha profissional, também visou o interesse voltado para o desenvolvimento integral do educando como cidadão. A 
orientação era considerada como "a panaceia para todos os fracassos dos processos educativos" (Freire, 1940, apud Grinspun, 1983, p. 58).

Diante desse contexto, o ano de 1942 foi considerado o marco da consolidação da Orientação Educacional a partir da Lei Orgânica do Ensino Industrial n ${ }^{\circ} 4043$, de 30 de janeiro de 1942, que institui a Orientação Educacional em cada estabelecimento de ensino industrial ou escola técnica. Ainda, no mesmo ano, introduziu-se a Orientação Educacional no ensino secundário a Lei Federal n. ${ }^{\circ}$ 4244, de 09 de abril de 1942. Nesse interim, a lei no 6.141, de 28 de dezembro de 1943, nomeada como Lei Orgânica do Ensino Comercial, no capítulo III prevê a presença do orientador educacional em seu corpo docente.

Dessa maneira, a Lei Orgânica do Ensino Industrial (Redação dada pelo Decreto Lei $\mathrm{n}^{\circ}$ 8.680, de 1946) traz no artigo 50, como objetivo da Orientação Educacional, o desenvolvimento dos educandos em uma perspectiva mais social. Em 1957 ocorre o I Simpósio de Orientação Educacional, no qual o orientador educacional teve sua figura carismática com uma característica apontada: "seu coração universal deve poder alojar no seu carinho, a cada um segundo, a necessidade do momento" (Grinspun, 2011, p. 23).

Neste processo construtivo, a Orientação Educacional foi se consagrando e assim, tornou-se assunto da LDB 4024 de 1961. Nesse espaço de conquistas, conforme Grinspun (2011), destaca-se a formação de orientadores educacionais tanto para os cursos de nível primário quanto secundário.

Em 1970 foi realizado o primeiro Congresso Brasileiro de Orientação Educacional, em Brasília, onde emergiu a inquietação para que se legitimasse adequadamente as funções do orientador educacional, a formação profissional e desempenho de suas atribuições (Garcia, 1990).

A partir disso, a LDB 5692/71 apresenta a relevância do papel do Orientador Educacional, prevendo a obrigatoriedade da presença deste nas escolas, incluindo o aconselhamento profissional e a mediação entre família, escola e comunidade, reconhecendo assim, sua importância para que se alcancem os objetivos propostos para o ensino. A referida lei retratou além dos aspectos supracitados, a questão sobre a formação, aperfeiçoamento e atualização dos Orientadores Educacionais, supervisores e demais especialistas em educação. Diante disto, os participantes tanto do Encontro de 1971 quanto do Congresso realizado em 1972 passaram a discutir a Lei 5692/71 e determinar suas funções na escola.

Conforme Garcia (1990), no IV Encontro Nacional em 1973, os participantes debateram sobre o cumprimento do artigo 10 da LDB 5692/71, que determinava a obrigatoriedade de um orientador educacional em cada escola. Entretanto, só acorreu em 1975 
no Município do Rio de Janeiro, ao mesmo tempo que se procurou regulamentar a Orientação Educacional como profissão. Torna-se necessário esclarecer que, na época em questão, os Congressos eram presididos por Ministros e Secretários de Educação, fato que viabilizou a entrega de um documento com contribuições para a reestruturação desta profissão para o então Ministro da Educação e Cultura Jarbas Passarinho.

Todavia, a partir do Decreto Federal no 72.846 de 26 de setembro de 1973, conforme o art. $1^{\circ}$, constitui como objeto da Orientação Educacional a assistência ao educando, individualmente ou em grupo, no âmbito do ensino de $1^{\circ}$ e $2^{\circ}$ graus, (atualmente ensinos fundamental e médio), visando o desenvolvimento integral e harmonioso de sua personalidade, ordenando e integrando os elementos que exercem influência em sua formação e preparando-o para o exercício das opções básicas.

Nesse sentido, houve a necessidade de buscar uma formação que contemplasse o preparo para que os orientadores educacionais dessem conta dessa harmonia de atributos que se fizeram necessários para a contribuição da formação plena do educando, assim para Grinspun (2011, p. 197):

[...] o Orientador é um especialista da educação - mas que tem compromisso com toda a educação que ocorre na escola, numa perspectiva de educador; é um profissional que se insere no campo do magistério e, portanto, tem os mesmos direitos e deveres, enquanto professor, que os demais.

Diante deste contexto, é importante salientar que o orientador educacional atua no campo do ensino, bem como, uma reflexão considerando-a como "[...] o ato de retomar, de reconsiderar os dados disponíveis, revisar, vasculhar numa busca constante de significado. É examinar detidamente, prestar atenção, analisar com cuidado" (Saviani, 2000, p. 16). Dessa forma é possível analisar o contexto histórico da trajetória do orientador enquanto educador, e posteriormente, compreender a contribuição da sua formação para o fazer pedagógico.

Na década de 1980 a educação voltou a ser questionada, sendo marcada por uma tendência tecnicista, deixando em segundo plano a educação preocupada com o desenvolvimento social e integral do educando. As manifestações a respeito da educação e da Orientação Educacional trouxeram muitas produções a respeito desse tema, e essas passaram a desqualificá-las.

Para Lück (2017) o foco das discussões estava centrado em formar uma consciência política por parte dos educadores. Nesta perspectiva, passou-se a dar mais atenção para formação teórica-política do Orientador Educacional que com a atuação pedagógica crítica, 


\title{
Res., Soc. Dev. 2019; 8(4):e1784961 \\ ISSN 2525-3409 | DOI: http://dx.doi.org/10.33448/rsd-v8i4.961
}

encaminhou para um maior comprometimento com os educandos. Todavia, há um descaso com o processo formativo do orientador educacional. $\mathrm{O}$ autor acrescenta:

\begin{abstract}
Deve-se ter em mente que a ação do orientador educacional será tão limitada quanto sua concepção sobre seu trabalho, daí a importância de promover o desenvolvimento da concepção teórica desse profissional. No entanto, essa concepção, por mais rica, coerente e ampla que seja, de nada valerá, se não for colocada em prática uma ação sistemática, organizada e seguramente direcionada. E essas condições somente são garantidas mediante a adoção de uma sistemática de planejamento de ações pedagógicas (Lück, 2017, p. 15).
\end{abstract}

Mediante isso, a Orientação Educacional chegou a ser definida como "anti-Orientação Educacional" (Lück, 2017, p. 19), e devido ao menosprezo por essa tendência tecnicista e simplista, foi apontada como dependente das classes dominantes e do capitalismo. Esses aspectos tiveram fortes repercussões na década de 1990 tanto na formação dos orientadores educacionais quanto nas instituições de ensino que não realizaram concursos para a contratação de orientadores educacionais.

Esse entendimento implicou na extinção da Federação de Orientadores Educacionais, em 1991, fazendo com que estes profissionais deixassem de ter a sua representatividade de forma mais expressiva, pois passaram a fazer parte da Confederação de Trabalhadores em Educação (Grinspun, 2011; Lück, 2017).

Todavia, a LDB 9394/96 não mais instituiu a obrigatoriedade na presença do orientador educacional em todas as instituições educacionais como era previsto no art. 10 LDB 5692/71. Contudo, causa certa estranheza, ter-se uma lei em que ela mesma se contrapõe, pois de um lado dispensa a presença do orientador educacional não o trazendo mais no contexto da LDB 9394/96, porém em outro aspecto inclui como membro integrante da equipe diretiva (Lei 9394/96 art. 14), no momento da instituição da gestão democrática.

Vale ressaltar que a mesma lei, em todo seu texto, referência a Orientação Educacional apenas duas vezes, sendo uma no inciso II do art. 61 a que inclui o orientador dentre os trabalhadores em educação, referenda:

Trabalhadores em educação portadores de diploma de pedagogia, com habilitação em administração, planejamento, supervisão, inspeção e orientação educacional, bem como com títulos de mestrado ou doutorado nas mesmas áreas (Lei nº 9394, 1996).

A outra acontece quando versa sobre a formação dos profissionais de educação no art. 64:

A formação de profissionais de educação para administração, planejamento, inspeção, supervisão e orientação educacional para a educação básica, será feita em cursos de graduação em pedagogia ou em nível de pós-graduação, a critério da 
instituição de ensino, garantida, nesta formação, a base comum nacional (Lei $\mathrm{n}^{\circ}$ 9394, 1996).

Conforme a redação do artigo 64 da LDB 9394/96 tem-se a formação do orientador educacional desenvolvida pelos cursos de graduação em Pedagogia. A resolução CNE/LLFCP $\mathrm{N}^{\mathrm{o}}$ 1, de 15 de maio de 2006, que institui as Diretrizes Curriculares Nacionais para o Curso de Graduação em Pedagogia, (licenciatura) ressalta que essa formação é conferida exclusivamente por cursos de pós-graduação específicos que habilitem para a Orientação Educacional.

A LDB 9394/96 não determina mais a obrigatoriedade de um orientador educacional em cada escola, mas institui a gestão democrática, que tem suas normas definidas pelos sistemas de ensino. Assim, a Figura 2, apresentada na obra de Libâneo (2017), retrata de forma sintética a configuração dos integrantes de uma gestão democrática.

Figura 2 - Estrutura básica das funções de uma gestão democrática.

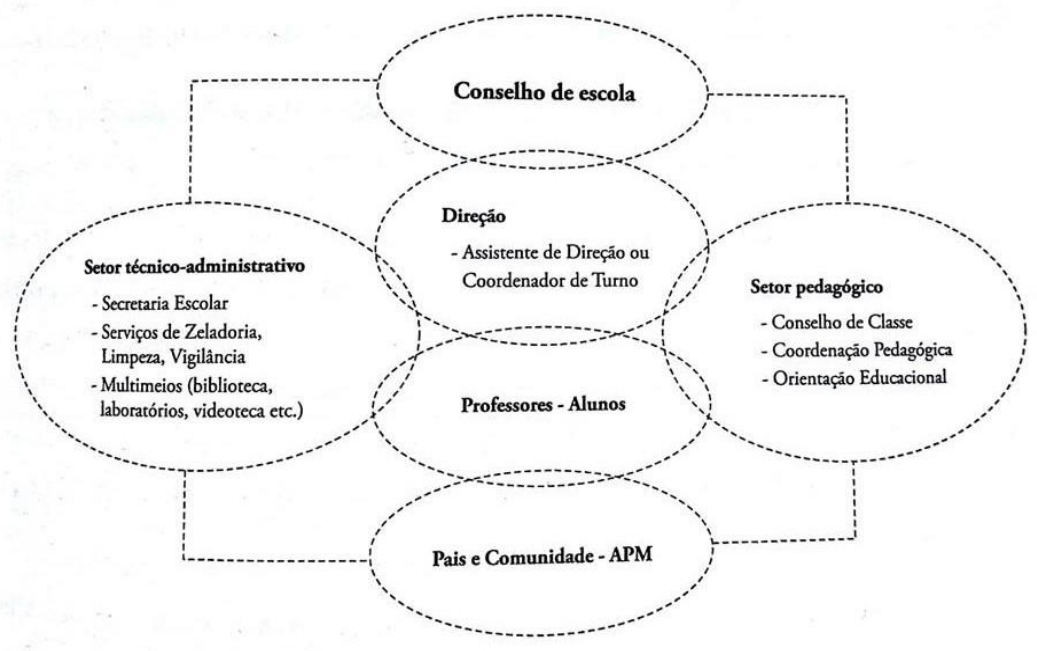

Fonte: Libâneo, J. C. Organização e gestão da escola: teoria e prática. 6 ed. São Paulo: Heccus Editora, 2017, p. 107.

Para Bugone, Dalabetha e Bagnara (2016) torna-se necessário construir uma escola com autonomia, na qual os profissionais precisam ter objetivos definidos, assim como a “educação é um processo contínuo que envolve coordenação e orientação da prática educacional de forma coletiva, a qual não se desenvolve de forma linear no contexto histórico, mas que se modifica a todo instante" (2016, p. 04). Percebe-se, então, que o orientador educacional faz parte dessa configuração e, portanto, a sua contribuição é imprescindível 
ISSN 2525-3409 | DOI: http://dx.doi.org/10.33448/rsd-v8i4.961

nessa conjuntura, uma vez que o processo de gestão escolar se desenvolve coletivamente no diálogo entre os integrantes de todos os segmentos.

\section{O Orientador Educacional no Contexto da Rede Municipal de Ensino de Santa Maria, RS}

A cidade de Santa Maria está localizada no coração do Rio Grande do Sul, (Figura 3), tendo como seus distritos: Arroio do Sol (Antigo Arroio do Só), Arroio Grande, Boca do Monte, Pains, Palma, Passo do Verde, Santa Flora, Santo Antão e São Valentim. De acordo com o último censo $(2010)^{1}$ a população era de 261.031 pessoas. Quanto a educação, a taxa de escolarização da população de 6 a 14 anos, deixa a cidade de Santa Maria na posição 1909 dentre as 5570 cidades brasileiras em 2010. A cidade conta com 78 escolas da rede municipal de ensino, 42 da rede estadual, 4 da rede federal para atenderem aos educandos do ensino básico ao ensino médio, e ainda com 3 faculdades e 2 universidades com cursos de graduação e de pós-graduação.

Figura 3: Mapa do Rio Grande do Sul - Brasil.

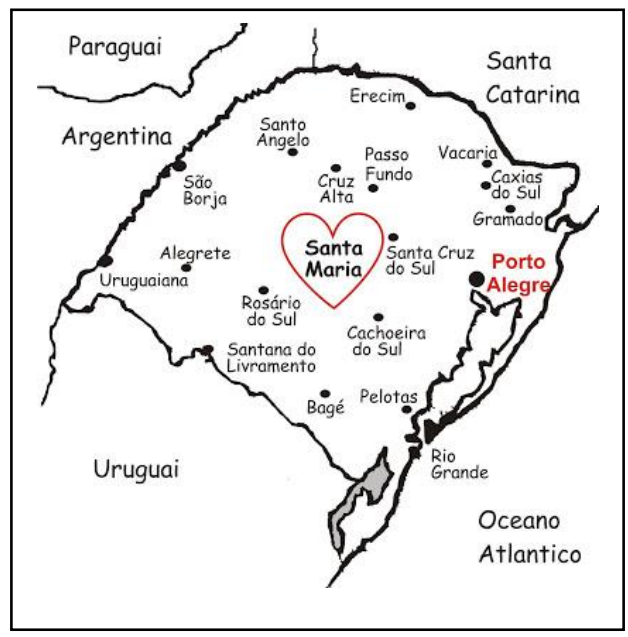

Fonte: Disponível em: http://santamaria-rs-brasil.blogspot.com/2009/12/mapa-com-santa-maria.html. Acesso em: 28 dez. 2018.

\footnotetext{
${ }^{1}$ Disponível em: https://censo2010.ibge.gov.br/ Acesso em 25 set 2018.
} 
A Rede Municipal de Ensino de Santa Maria é constituída de setenta e oito (78) escolas, sendo vinte e duas (22) EMEIs ${ }^{2}$, uma (01) escola do campo e três (03) escolas de educação infantil conveniadas com a Mitra ${ }^{3}$; cinquenta e quatro (54) $\mathrm{EMEF}^{4}$, dessas nove (09) são escolas do campo e doze (12) que ofertam a Educação de Jovens e Adultos; duas (02) escolas profissionalizantes, EMAI ${ }^{5}$ e EMAET ${ }^{6}$. A Rede Municipal de Santa Maria atende aproximadamente 20.000 alunos, contando em seu quadro de recursos humanos com 1.700 professores, cuja formação destaca-se que: 100\% possuem nível de graduação, $84 \%$ nível de especialista, $11 \%$ nível de mestrado e $5 \%$ nível de doutorado.

Quando se trata de ensino e aprendizagem escolar para contextualizar a RME/SM é importante referendar os dados do Índice de Desenvolvimento da Educação Básica (IDEB) ${ }^{7}$. Conforme dados do site $^{8}$ do IDEB no último ano em que foram mensurados os resultados da avaliação que foi em 2015 existia nos anos iniciais RME/SM uma meta a ser atingida, sendo essa a nota 5,0, e esse índice a ultrapassou atingindo de 5.4. Já nos anos finais, o índice cresceu em relação ao anterior. Porém, a meta estabelecida (4.7) não foi alcançada, já que atingiu 4,4. Logo, entende-se que esses índices são um sinalizador de que é preciso unir esforços coletivos no cotidiano da escola, para que se obtenham melhores resultados na qualidade do ensino e aprendizagem escolar.

Conforme o que foi apontado, justifica-se o trabalho de uma equipe interdisciplinar na escola, um trabalho em rede com toda a equipe gestora (diretor, vice-diretor, coordenador pedagógico, orientador educacional), professores/educadores, que possam vir a apoiar todo processo de ensino aprendizagem auxiliando os educandos a atingirem as metas delineadas.

Nessa perspectiva, o que se visa é que essa rede não só proporcione o alcance com êxito dos índices esperados, mas juntamente, possibilite a superação dos mesmos. Torna-se, nesse viés, importante ressaltar que esta equipe poderá não estar completa em muitas escolas, devido à Lei Municipal 4740/03 que extingue o cargo de orientador educacional das escolas de nosso município, visto que ainda permanecem como integrantes da equipe gestora da escola.

\footnotetext{
${ }^{2}$ EMEI- Escola Municipal de Educação Infantil

${ }^{3}$ MITRA- Mitra Diocesana- congregação ligada à igreja católica

${ }^{4}$ EMEF- Escola Municipal de Ensino Fundamental

${ }^{5}$ EMAI- Escola Municipal de Aprendizagem Industrial

${ }^{6}$ EMAET- Escola Municipal de Artes Eduardo Trevisan

${ }^{7}$ Disponível em: http://www.qedu.org.br/brasil/ideb. Acesso em 10 maio 2018.

${ }^{8}$ QEdu - é um portal aberto e gratuito, com todas as informações públicas sobre a qualidade do aprendizado em cada escola, município e estado do Brasil. Ele oferece dados da Prova Brasil, do Censo Escolar, do Ideb e do Enem de forma simples e acessível.
} 
Em Santa Maria, a Lei Municipal no 4696/03 de 22 de setembro de 2003 regulamenta o plano de carreira do magistério público do município em consonância com a Lei Orgânica do Município, desta forma conforme disposto no Art. $3^{\circ}$, esclarece que são membros do magistério, ou profissionais da educação os professores que ocupam cargos e funções na rede pública e aqueles que desempenham atividades que possibilitam alcançar os objetivos pretendidos na educação. Assim, conforme o Art. 18 da Lei Municipal nº 4696/03, não mais prevê concurso público para áreas de Orientação Educacional e desta forma o Art. 56 da mesma lei, vindo a corroborar com o Art.18, extingue este cargo no município de Santa Maria.

Nesse contexto, o cargo de orientador educacional que era preenchido através de concurso público para especialistas em educação deixa de existir, restando, portanto, a função ser exercida por professores, docentes concursados pelo município, geralmente a convite da direção da escola e autorizados pela Secretaria de Educação do Município.

Em suma, a partir da lei supracitada (Lei Municipal n 4696/03), a RME/SM deixou de oferecer concurso para preenchimento de vagas ao cargo de orientador educacional, mas permite que as escolas tenham em seu quadro funcional professores que exerçam a função, desde que possuam a habilitação para a mesma.

Apesar de encontrarmos no dicionário os vocábulos "cargo" e "função" como sinônimos, no contexto do plano de carreira dos profissionais do município, eles são considerados distintos. Visto que é importante estabelecer aqui esta diferença para que assim se obtenha um melhor entendimento no que tange a respeito do orientador educacional em Santa Maria.

De acordo com o capítulo 2 art. $6^{\circ}$ da Lei Municipal No 4696/03, de 22 de setembro de 2003, “cargo é o conjunto de atribuições e responsabilidades cometidas ao membro do Magistério, mantidas as características de criação por lei, denominação própria, número certo e retribuição pecuniária padronizada". Desse modo, um profissional docente que tenha o cargo (área para qual foi contratada ou prestou concurso) de professor, pode exercer a função (papel ao qual foi designado naquele momento) de diretor da escola, coordenador pedagógico, de professor, ou (como no caso da análise deste trabalho) orientador educacional.

Consideram-se professores habilitados para exercerem a função de orientadores educacionais na RME/SM aqueles quais de acordo com os níveis especificados no art. 16 da Lei Municipal No 4696/03, de 22 de setembro de 2003, têm habilitação em nível superior, graduação em curso de licenciatura plena, seguida de curso de pós-graduação em nível de especialização em Orientação Educacional ou gestão escolar habilitado para a Orientação 
Educacional lato sensu, stricto sensu ou graduação em Pedagogia. Cabe salientar que os cursos de Pedagogia, atualmente, não mais habilitam o trabalho em Orientação Educacional.

A partir de estudos em documentos fornecidos pela mantenedora verificou-se que em muitas escolas municipais não existe mais a presença desse profissional, entretanto, quando se busca na lei de gestão democrática, constata-se que o orientador é parte integrante da equipe diretiva.

De acordo com a Lei Municipal 4740/03 de 24 de dezembro de 2003, que institui a gestão democrática no que tange ao artigo $6^{\circ}$ do capítulo III - da autonomia administrativa, no seu parágrafo único deixa claro que a equipe diretiva da Escola é composta pelo diretor (a), vice-diretor (a), coordenador (a) pedagógico (a) e orientador (a) educacional. Em suma, em consonância com a própria lei, as escolas municipais de Santa Maria que não têm, em sua gestão, a presença de um orientador educacional, não têm sua equipe diretiva completa.

De acordo com o quadro funcional fornecido pela Secretaria de Município de Santa Maria, no ano de 2017, das 78 escolas municipais, apenas 29 contavam em sua equipe com a presença deste profissional independentemente de cargo ou função.

Os professores da rede municipal atuam no mínimo há três anos como orientadores educacionais na RME-SM, independentemente de terem sido lotados nas escolas através de um cargo ${ }^{9}$ ou de uma função ${ }^{10}$.

Atualmente, poucos os professores têm o cargo de orientadores educacionais, a maioria exerce a função devido a extinção do mesmo em 2003, desta forma os professores exercendo apenas a função de orientadores educacionais não podem ter mais que 20 horas no estabelecimento de ensino, pois não há regime suplementar ${ }^{11}$ para este trabalho. Desse modo, algumas escolas têm o orientador educacional em apenas um turno, o que direciona à necessidade em se optar por atender aos alunos da Educação Infantil, dos Anos Iniciais ( $1^{\circ}$ ao $5^{\circ}$ anos do Ensino Fundamental) ou aos dos Anos Finais ( $6^{\circ}$ ao $9^{\circ}$ anos do Ensino Fundamental, além do E.J.A. Diante da demanda de suas escolas, alguns orientadores educacionais dividem sua carga horária entre os turnos.

Mesmo que dentro das políticas da RME/SM se tenham perspectivas para que todas as escolas tenham um orientador educacional em suas equipes gestoras, enquanto não houver alterações no plano de carreira com a inclusão deste cargo, torna-se um pouco mais difícil que

\footnotetext{
${ }^{9}$ Cargo - função para a qual prestaram concurso.

${ }^{10}$ Função- atividade que exercem na escola, apesar de terem feito concurso para o cargo de professor.

${ }^{11}$ Regime suplementar de trabalho
} 
tal objetivo seja atendido, uma vez que será preciso que um professor se afaste da sua função da docência, para a qual fez o concurso, para atender a demanda da Orientação Educacional.

Diante da importância do papel do orientador educacional nas escolas, destaca-se que é possível apontar soluções, tais como: oferecer aos professores já concursados e habilitados que apresentem interesse em trocar sua função de professor para orientador, cabendo então à Secretaria de Educação o provimento dessas vagas através de concurso ou suplementação, ou ainda retomar a realização de concurso para o cargo de orientador para que se possa suprir a ausência destes nas escolas que ainda não têm sua equipe diretiva completa.

Mediante isso, de acordo com Libâneo (2017), as concepções de gestão escolar refletem diferentes posicionamentos políticos, bem como, as concepções do papel da escola e da formação humana. Isto significa que, o modo como a escola se organiza e estrutura possui um caráter pedagógico e depende de objetivos mais amplos sobre a relação escola com a conservação/transformação social.

Assim sendo, no contexto da RME/SM, é necessária a viabilização da criação de políticas onde o papel do orientador educacional seja valorizado, de modo que ele possa vir a contribuir com os desafios que atualmente são enfrentados pela gestão escolar, atuando como parte de uma equipe interdisciplinar que seja capaz de auxiliar especialmente no que se refere ao processo de ensino e aprendizagem.

Cabe agora um questionamento de como contar com um orientador educacional e determinar o seu papel; a sua importância na RME/SM; como ele poderá auxiliar nas melhorias dos índices do IDEB e auxiliar os estudantes em seu desenvolvimento integral se, sequer $40 \%$ das escolas têm a presença desse educador na sua equipe gestora?

Estas questões apontadas não serão resolvidas imediatamente, pois são necessárias políticas públicas exequíveis para que isto ocorra; tampouco apenas a presença do orientador educacional resolverá todos os problemas do ensino em nosso município, mas sua atuação poderia auxiliar na resolução dos problemas mais iminentes.

\section{Metodologia}

A metodologia está embasada em uma pesquisa de abordagem qualitativa do tipo bibliográfica e documental, uma vez que o problema a ser respondido e discutido envolvem os marcos legais e conceituais da Orientação Educacional.

Para Minayo (2001) a pesquisa qualitativa olha para os aspectos da realidade que não são quantificados, ou seja, preocupa-se com a compreensão e explicação da dinâmica das relações sociais. 
A autora dá ênfase a pesquisa qualitativa que trabalha com uma variedade de significados, motivos, aspirações, crenças, valores e atitudes, dos processos e dos fenômenos que não podem ser reduzidos à quantificações.

Nesse sentido a pesquisa é do tipo documental, pois recorre à análise de fontes primárias e secundárias, na interpretação dos dados (Minayo, 2001).

\section{Resultados e discussão}

Ainda que não se reconheça o orientador educacional como um profissional imprescindível no sistema educacional, em que a própria LDB 9496/96 não traz mais a obrigatoriedade de sua presença, pode-se afirmar que para o contexto educacional no qual estamos inseridos esse profissional é de extrema importância, pois ele tem papel fundamental na formação integral do educando.

As atribuições do orientador educacional dividem-se em: mediar conflitos em diversos segmentos (aluno/aluno, aluno/professor, professor/colegas); auxiliar na execução de projetos e nos problemas de aprendizagem; diálogos com os alunos sobre valores e atitudes, mesmo tendo suas atividades descritas no Projeto Político Pedagógico (P.P.P.) da escola em que atuam, por vezes o trabalho realizado vai além destas para que se atenda às necessidades da comunidade escolar, uma vez suas atribuições implicam em mediar conflitos em diversos segmentos (aluno/aluno, aluno/professor, professor/colegas); auxiliar na elaboração e execução de projetos e nos desafios do ensino e aprendizagem;

Ao discutir sobre a historicidade dos orientadores educacionais de Santa Maria pretendeu-se demonstrar a necessidade de resgatar o profissional da Orientação Educacional na rede municipal onde ele possa realizar um trabalho interdisciplinar em que haja um elo entre o a formação de valores e o conhecimento dos conteúdos específicos dos componentes curriculares, voltados para a aprendizagem significativa e a formação integral do educando.

\section{Conclusão}

Desse modo, entende-se que é necessária a viabilização da criação de políticas onde o papel do orientador educacional seja valorizado, de modo que ele possa vir a contribuir com os desafios que atualmente são enfrentados pela gestão escolar, atuando como parte de uma equipe interdisciplinar que seja capaz de auxiliar especialmente no que se refere aos processos de ensino e aprendizagem. 
Nesse viés, destaca-se a importância da gestão numa perspectiva democrática, com uma liderança compartilhada e que venha auxiliar na atuação de toda a comunidade escolar para adotar meios de alcançar a superação das dificuldades encontradas no processo de ensino e aprendizagem. Assim, poderá ser possível ter melhores resultados na educação com a existência de políticas públicas que retornem claramente com a obrigatoriedade da presença dos orientadores educacionais nas escolas.

\section{Referências}

Bugone, A. C., Dalabetha, A., \& Bagnara, C. I. (2016). O orientador educacional e seus desafios no contexto escolar. Instituto de Desenvolvimento Educacional do Alto Uruguai IDEAU, 11(23). Recuperado em 24 janeiro, 2019, de https://www.ideau.com.br/getulio/restrito/upload/revistasartigos/360_1.pdf

Decreto $n^{\circ} 72.846$, de 26 de setembro de 1973. Regulamentada a Lei n. ${ }^{\circ} 5.564$, de 21 de dezembro de 1968, que provê sobre o exercício da profissão de orientador educacional. Recuperado em 04 março, 2018, de http://www.planalto.gov.br/ccivil_03/decreto/19701979/d72846.htm

Decreto Lei $n^{o}$ 8.680, de 15 de janeiro de 1946. Dispõe sobre a Lei Orgânica do Ensino Industrial. Recuperado em 05 março, 2017, de http://www.planalto.gov.br/ccivil_03/decretolei/1937-1946/Del8680.html

Decreto Lei $n^{o}$ 6.141, de 28 de dezembro de 1943. Dispõe sobre a Lei Orgânica do Ensino Comercial. Recuperado em 05 março, 2017, de http://www2.camara.leg.br/legin/fed/declei/1940-1949/decreto-lei-6141-28-dezembro-1943416183-publicacaooriginal-1-pe.html

Garcia, R. L. (org) Orientação Educacional e o Trabalho na Escola. São Paulo: Edições Loyola, 1990.

Grinspun, M. (1983). Histórico da orientação educacional no Brasil. Fórum 2/1983. $\begin{array}{lllll}\text { Recuperado em } & 22 & \text { setembro, } & 2017, & \text { de }\end{array}$ http://bibliotecadigital.fgv.br/ojs/index.php/fe/article/viewFile/60676/58916

Grinspun, M. (2011). A Orientação educacional - Conflito de paradigmas e alternativas para a escola ( $\left.5^{\mathrm{a}} \mathrm{ed}\right)$. São Paulo: Cortez.

Grinspun, M. (2012). A prática dos Orientadores Educacionais (7ªed). São Paulo: Cortez.

Lei $n^{\circ}$ 9.394, de 20 de dezembro de 1996. Dispõe sobre a Lei de Diretrizes e Bases da Educação Nacional. Recuperado em 17 maio, 2018, de http://www.planalto.gov.br/ccivil_03/LEIS/L9394.htm

Lei Municipal $n^{o}$ 4696/03, de 22 de setembro de 2003. Estabelece o Plano de Carreira do Magistério Público do município, institui o respectivo quadro de cargos e dá outras 
Res., Soc. Dev. 2019; 8(4):e1784961

ISSN 2525-3409 | DOI: http://dx.doi.org/10.33448/rsd-v8i4.961

providências. $\quad$ Recuperado em 05 março, 2018, de http://www.santamaria.rs.gov.br/docs/Pub_23080226-66.pdf

Libâneo, J. C. (2017). Organização e Gestão da Escola Teoria e Prática (6 ${ }^{\mathrm{a}}$ ed. revisada e ampliada, $2^{a}$ tiragem). São Paulo: Heccus.

Lück, H. (2017). Planejamento em Orientação Escolar (23ª ed.). Petrópolis: Vozes.

Minayo, M. C. (1992). O desafio do conhecimento: pesquisa qualitativa em saúde. São PauloRio de Janeiro: HUCITEC-ABRASCO.

Resolução CNE/CP $n^{\circ}$ 1, de 15 de maio de 2006. Institui Diretrizes Curriculares Nacionais para o Curso de Graduação em Pedagogia, licenciatura. Recuperado em 18 março, 2018, de http://portal.mec.gov.br/cne/arquivos/pdf/rcp01_06.pdf

Saviani, D. (2000). Educação: do senso comum à consciência filosófica. Revista Campinas, 13. São Paulo: Autores Associados.

\section{Porcentagem de contribuição de cada autor no manuscrito}

Janete Allassia Drebes Wouters - 50\%

Eliane Aparecida Galvão dos Santos - 50\% 